\begin{tabular}{|c|c|c|}
\hline 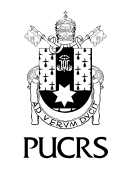 & $\begin{array}{l}\text { ESCOLA DE } \\
\text { HUMANIDADES }\end{array}$ & $\begin{array}{l}\text { Revista Digital do Programa de Pós-Graduação em Letras da PUCRS } \\
\text { Letrônica, Porto Alegre, v. 14, n. 2, p. 1-9, abr.-jun. } 2021 \\
\text { e-ISSN: } 1984-4301\end{array}$ \\
\hline (Ittp: //dx & org/10.15448/1984-4301.2021.2.38712 & \\
\hline
\end{tabular}

SEÇÃO: ARTIGOS

\title{
Letramento dominante e prática social: reflexões sobre a linguagem jurídica e a relação de poder com o jurisdicionado
}

\author{
Dominant literacy and social practice: reflections about the legal language and the \\ power relationship with the jurisdicted
}

\section{Luzia Fernandes do Nascimento ${ }^{1}$ \\ orcid.org/0000-0002-3184-9344 luzjus@hotmail.com}

Recebido em: 28/07/2020. Aprovado em: 28/09/2020. Publicado em: 10/08/2021.
Resumo: Sabe-se que o objetivo precipuo da lingua em qualquer comunidade de fala é comunicar. No âmbito dos espaços jurídicos (tribunais, fóruns, sala de audiência ou secretarias forenses), as habilidades de leitura e escrita são de suma importância para que o cidadão participe juridicamente da sociedade de modo abrangente e tenha a tão apregoada garantia de acesso à Justiça, consoante dispõe o texto constitucional brasileiro. Neste artigo, tem-se como objetivo propor uma reflexão sobre até que ponto a linguagem juridica representa um instrumento de poder e segregação entre a Justiça e o jurisdicionado, considerando o estilo linguistico presente nas decisões judiciais e em outros textos emanados dos espaços jurídicos, como também a falta de letramento social para atuação do indivíduo nos espaços institucionalizados. Essa reflexão ancora-se nos postulados dos Novos Estudos de Letramento, de Street (1993), Ângela Kleiman (1995) e Tfouni (1995), e também no conceito de poder simbólico do sociólogo Pierre Bourdieu (1989). Por fim, avoca-se a ideia do uso de uma linguagem juridica capaz de inserir o jurisdicionado no universo das decisões judiciais, em detrimento do purismo linguístico, muitas vezes, ininteligivel, com foco em uma decisão judicial emanada de um juiz do TRF 4, no ano de 2015.

Palavras-chave: Letramento. Linguagem jurídica. Jurisdicionado. Poder simbólico.

\begin{abstract}
Know who the language of the language in any community of speech is to communicate. In the space of legal spaces, (courts, forums, courtroom or forensic secretaries), as reading and writing skills are of important importance to the citizen participant and in such a comprehensive manner and have the same guarantee of access to justice, provision according to the Brazilian constitutional text. This article aims to reflect, to what extent, legal language represents an instrument of power and segregation between the and justice, considering the linguistic style present in judicial decisions and the lack of social literacy for the performance of man in spaces institutionalized. This analysis was carried out in the United States after the social literacy of Angela Kleiman (1995). Tfouni (1995) and Soares (2004) and, although it is, the concept of symbolic power of the sociologist Pierre Bourdieu (1989). Why, if the idea is of a certain sense, it is unintelligible, unintelligible, with a judicial decision emanating from a TRF judge. in the year 2015. Keywords: Literacy. Legal language. Jurisdiction. Symbolic Power.
\end{abstract}

\section{Introdução}

Hodiernamente, são grandes os desafios para formar cidadãos proficientes em significar a realidade que os cerca. Não são raras as pesquisas que apontam que, apesar do crescente avanço na universalização do acesso à educação básica, a escola ainda é falha no que diz respeito a instrumentalizar o individuo para aspectos básicos sobre leitura e escrita. Em decorrência desse processo falho, tem-se como produto o chamado 
"analfabeto funcional", denominação dada a brasileiros que apresentam limitações para fazer uso da leitura, da escrita e de cálculos matemáticos em situações mais comezinhas do cotidiano.

O domínio da leitura e da escrita constitui-se como indissociável da atuação no meio social, essencial para o engajamento do indivíduo como membro de um grupo social disposto a agir, interagir, confrontar e ocupar os espaços de poder possibilitados pelos instrumentais de leitura e escrita. Nesse sentido, a falta desse domínio acaba por condenar o cidadão a um apartheid social, considerando o valor imprescindivel do universo das letras como instrumento de interação em uma sociedade letrada, principalmente no que tange à atuação do cidadão nos espaços jurídicos.

É nesse contexto que surge o letramento como prática necessária para a atuação do individuo em uma instituição de extremo prestígio social, como é o caso do Poder Judiciário. Nesse sentido, verifica-se que os espaços jurídicos se assentam sobre práticas de "letramentos dominantes", expressão utilizada por alguns estudiosos dos Novos Estudos de Letramento (BARTON; HAMILTON, 1998) para se referir às práticas de leitura e escrita que estão intrinsecamente relacionadas às posições de poder. Essa expressão carrega uma multissignificação, podendo ser entendida como a prática de letramento para manter e/ou criar relações de dominação, como os usos dominantes do letramento, ou como formas institucionalizadas de utilização de textos, e assim por diante.

Em contrapartida, temos outros modelos de letramento com grau menor de prestígio vinculados às práticas de leitura e escrita distantes dos espaços institucionalizados, como a escola. Nesse aspecto, acabam surgindo práticas de letramento valorizadas e não valorizadas, promovendo um apagamento do indivíduo que não se apropria desse letramento dominante. É nesse sentido que Kleiman (1995), referenciando Street (1993), esclarece que as práticas de letramento constituem aspectos das estruturas de poder em uma sociedade, não se restringindo apenas ao aspecto cultural, isto é, as práticas de letramento mudam segundo o seu contexto, de modo que existem situações em que a escrita "constitui parte essencial para fazer sentido da situação, tanto em relação à interação entre os participantes com em relação aos processos e estratégias comunicativas" (KLEIMAN, 1995, p. 40). Tais situações são denominadas pela autora de "eventos de letramento".

Nesse mesmo viés, Heath (1982), inspirado na ideia de eventos de fala, define evento de letramento como situações em que a escrita se constitui como elemento intrínseco das interações dos participantes, bem como dos processos de interpretação dessas situações interacionais.

Diante disso, considerando que as práticas discursivas mudam de acordo com o seu contexto, têm-se os espaços jurídicos como aqueles em que se sobrepõe o letramento dominante constituindo-se como entrave no processo de comunicação entre a Justiça e o jurisdicionado que a ela recorre. Nesse contexto, a linguagem juridica, formalizada através de textos diversos e, mais especificamente, através das decisões emanadas dos julgadores, configura-se como instrumento segregador entre o cidadão, portador do letramento não valorizado, e a Justiça.

Nessa toada, o direito e a linguagem juridica são vistos pelo sociólogo Pierre Bourdieu (1989) como óbices do indivíduo ao sagrado postulado de acesso à Justiça e como forma de controle social. O autor considera a linguagem jurídica, tal como se apresenta, como manifestação de poder em que a comunicação depende de uma relação de poder desigual, à qual o sociólogo dá o nome de poder simbólico.

O enfoque dado por Bourdieu à linguagem não se restringe ao processo de comunicação, abrangendo as relações de autoridade, de valorização ou desvalorização dos diversos discursos que circulam nos mais variados contextos.

Com base nesse arcabouço teórico, em que se vincula o letramento dominante ao poder simbólico da linguagem jurídica no âmbito do espaço do poder judiciário, este artigo traz a análise de uma decisão prolatada por um membro da Justiça do Rio Grande do Sul. Trata-se de um acórdão cujo relator foi um juiz convocado da $4^{a}$ Turma do 
Tribunal Regional do Trabalho da 4 a Região (RS), Dr. João Batista de Matos Danda, o qual redigiu em uma linguagem mais simples, com o intuito de aproximar o Judiciário da população.

\section{Letramento dominante e prática social}

Quando se trata de letramento no Brasil, não se pode negligenciar a relação entre sujeito, linguagem e contexto social, segundo as ideias de Paulo Freire, cuja proposta de aquisição da leitura compreende a necessidade de interagir com o social, com a realidade na qual o indivíduo está inserido. Na esteira do pensamento de Freire (1981), a educação só é libertadora (Pedagogia da Libertação) quando se fundamenta na realidade concreta do educando, ou seja, o ato de acesso à cultura da escrita, por meio da leitura, não pode estar dissociado da cultura, da realidade do indivíduo ou do grupo envolvido.

Sobre o tema, Tfouni (1995) afirma que as perspectivas de letramento se colocam favoravelmente à tese da grande divisa, segundo a qual há uma separação radical entre os usos orais e os usos escritos da língua, sendo os escritos superiores. Nesse ponto de vista, a estudiosa alinha-se ao pensamento de Street (1984) que, numa postura crítica ao grafocentrismo de alguns autores, estabelece uma versão moderna da teoria da grande divisa, em que a relação entre as modalidades oral e escrita da língua aponta para um hibridismo, ou um imbricamento de formas, de códigos gráfico-visuais, de gêneros discursivos e modelos textuais.

Considerando todos esses aspectos em torno do letramento, Mortatti (2004) sustenta que os estudos em torno desse campo de saber, dada a natureza complexa do tema, resulta em um conceito plural, considerando os aspectos diversos que envolvem esse fenômeno. As caracteristicas que permeiam esse campo do saber, tanto de interesse das ciências da educação, como das ciências linguísticas

[...] obrigam a considerar a pluralidade do conceito de letramento, a fim de evitar a diluição das diferenças por meio de fórmulas simplificadoras que visem à fixidez e homogeneização do que é ainda provisório e heterogêneo, como fenômeno e como conhecimento em construção nesse momento histórico[...]. (MORTATTI, 2004, p. 94-96)

No livro Os significados do letramento: uma nova perspectiva sobre a prática social da escrita, Ângela Kleiman reafirma a complexidade e variação dos tipos de estudos sobre letramento e o define como "um conjunto de práticas sociais que usam a escrita, enquanto sistema simbólico e enquanto tecnologia, em contextos específicos, para objetivos especíicos" (KLEIMAN, 1995, p. 19).

Assim como a escrita é usada no bojo das práticas sociais de letramento, Magalhães Neto (2017) assevera que a leitura e a fala também constituem elementos indispensáveis para as práticas sociais de letramento, uma vez que contribuem para o desenvolvimento social e em todas as atividades do individuo, das mais simples às mais complexas.

Kleiman (1995) valida o pensamento de Tfouni (1995) de que um individuo pode ser letrado sem, contudo, saber ler e escrever. Nesses termos, cita vários espaços em que esse processo de letramento acontece, denominados de agências de letramento, elegendo o espaço escolar como o mais importante, porém restrito à aquisição do código escrito, concebido em termos de competência individual, ao passo que a familia, a igreja, a rua, o local de trabalho constituem-se como agências de letramento como prática social.

Quanto às práticas de uso da escrita, a autora retoma as concepções de letramento denominado "modelo autônomo" e "modelo ideológico", de Street (1984), traçando um paralelo entre as duas concepções. O modelo autônomo está centrado na competência individual, numa relação entre a aquisição da escrita e o desenvolvimento cognitivo. É no âmbito desse modelo que se assenta a teoria da grande divisa, já citada, denominada por Ângela Kleiman como a dicotomização entre a oralidade e a escrita.

No modelo autônomo, segundo Kleiman (1995), os problemas de aquisição da escrita e da leitura são analisados à luz das competências e habilidades individuais cognitivas do indivíduo, sem vinculação com a realidade social em que esse individuo está inserido. Nesses termos, 
O modelo autônomo tem o agravante de atribuir o fracasso e a responsabilidade por esse fracasso ao indivíduo que pertence ao grupo dos pobres e marginalizados nas sociedades tecnológicas [...] assim, uma analfabeta paraibana, estado onde mais de 50\% da população é analfabeta, atribui primeiro aos seus pais essa responsabilidade ao relatar que "nunca frequentou a escola quando criança 'por causa da ignorância dos pais'" e logo culpa-se a si mesma por ter desistido da escola quando adulta. Apesar do relato que faz das condições em que tentou estudar ("as aulas eram à noite e ela dormia, cansada do trabalho de faxineira que tinha de dia"). (KLEIMAN, 1995, p. 38)

O modelo ideológico é definido pela autora na mesma esteira de Street, em que as práticas de aquisição da escrita, ou práticas letradas, são determinadas pelo contexto social, atrelando as práticas de letramento aos aspectos culturais e, ainda, e às estruturas de poder de uma sociedade. Para tanto, Kleiman (1995, p. 39) afirma que:

O modelo ideológico, portanto, não deve ser entendido como uma negação de resultados especificos dos estudos realizados na concepção autônoma do letramento. Os correlatos cognitivos da aquisição da escrita na escola devem ser entendidos em relação às estruturas culturais e de poder que o contexto de aquisição da escrita na escola representa.

Kleiman (1995) estabelece o conceito de eventos de letramento com fulcro em um estudo etnográfico de comunidades do sul dos Estados Unidos, de Heath (1982, apud KLEIMAN, 1995) como situações em que a escrita é parte essencial numa relação de interação e de processos interpretativos.

Com base no pensamento de Street (1984), Tfouni (1988) assevera que não existe, nas sociedades modernas, o letramento "grau zero", que equivaleria ao "iletramento", ou ao analfabetismo. Na visão da autora, o que existem são graus de letramento, em decorrência das diferentes práticas discursivas de grupos socioeconômicos distintos.

Em sintese, todos esses autores concebem letramento como o uso da leitura e da escritura em práticas sociais em que os sujeitos, embora não saibam ler nem escrever (analfabetos), podem ser, de certa forma, letrados, uma vez que utilizam a leitura e a escrita em situações de interação. Esse uso da escrita e da leitura por indivíduos que não sabem ler nem escrever é revestido de estratégias que os permitem interagir no seu contexto social. É respaldado nesse pensamento, que se estabelece uma relação intrinseca entre letramento e práticas sociais, caracterizando-o como o conjunto de habilidades necessárias para que o indivíduo se sobressaia em seu contexto social, o chamado letramento funcional.

Em 2002, Magda Soares publica o artigo intitulado "Novas práticas de leitura e escrita: letramento e cibercultura", na revista Educação \& Sociedade. Como é recorrente nas obras que tratam desse campo de conhecimento, desde meados dos anos 1980, a autora trata da inexatidão conceitual do termo, o que a leva a afirmar que se trata de um fenômeno de conceitos plurais, no entanto, reafirma a sua visão sobre letramento, colocando-o em oposição a analfabetismo.

Segundo Soares (2002), existe uma relação estreita entre letramento e tecnologias digitais de leitura e escrita. Diante disso, levanta reflexões sobre os impactos da tecnologia da escrita digital sobre os espaços de letramento, que resultam em vários efeitos sociais, cognitivos e discursivos. Diante desse cenário tecnológico ocupado pela leitura e pela escrita, presencia-se o surgimento de modalidades diferentes de letramento, motivo pelo qual a estudiosa sugere que se pluralize o termo letramento, considerando que não existe letramento, mas letramentos.

A realidade cultural que está sendo desenhada, ou que já domina os espaços sociais a partir do uso da rede de computadores e de outros suportes tecnológicos também se faz presente nas escolas. Sendo o letramento a condição dada ao indivíduo para interagir em seu cotidiano, o termo ganha uma nova perspectiva em face dessas demandas que emergem no âmbito das práticas sociais, fazendo surgir o hipertexto.

\section{0 poder simbólico de Pierre Bourdieu}

A linguagem no universo juridico está inserida no letramento dominante, muito distante de outros tipos de letramentos não canônicos e marginalizados, o que acaba por afastar o cidadão do espaço jurídico, numa afronta ao princípio constitucional de acesso à Justiça. A prática do letramento domi- 
nante no seio dos espaços jurídicos limita-se aos profissionais que postulam em nome de outrem o direito que acreditam ter, no entanto, até mesmo para esses profissionais que militam na seara jurídica, não são raras as vezes em que o purismo linguístico vai de encontro ao objetivo maior da linguagem, qual seja, incluir, e não segregar.

Nesse sentido, o direito e a linguagem jurídica se revestem de manifestação de poder limitador da inserção do individuo nos espaços de prestígio social, visto que as relações de comunicação são relações de poder fundadas em um arbítrio, de violência simbólica, socialmente instituídas, conforme estabelece Bourdieu (1989). Nesse ponto, o poder simbólico da linguagem pressupõe que os dominados se submetem espontaneamente ao controle socialmente construido.

Dessa forma, é notório o fosso entre as normas jurídicas, as decisões judiciais elaboradas à luz do letramento dominante, e o demandante na esfera judicial, uma vez que todo esse arcabouço linguístico jurídico é criado para tornar inacessivel o seu discernimento na correlação com o jurisdicionado.

Nas palavras de Bourdieu (1989) o poder simbólico é consequência dos instrumentos de comunicação e conhecimento, tendo como característica a invisibilidade, uma vez que não é percebido pelos agentes que dele são vítimas e a ele se submetem. É essa característica da invisibilidade que mantém o jurisdicionado, no caso, na subserviência, significando o mundo juridico como natural e racional, o que fortalece o poder da linguagem dominante.

É nesses termos que, alicerçado no poder simbólico entre jurisdicionado e Justiça, Bourdieu (1989) afirma que a legitimidade da palavra não advém da linguagem por si só, tendo sua origem nas relações sociais que a sustentam e a produzem. Desta feita, são essas relações de poder que produzem e que desconhecem palavras, com o fito de manutenção dessas relações assimétricas, conforme se pode verificar, in verbis:

O poder simbólico como poder de constituir o dado pela enunciação, de fazer ver e fazer crer, de confirmar ou de transformar [...]. O que fazo poder das palavras e das palavras de ordem. poder de manter a ordem ou de a subverter, éa crença na legitimidade das palavras e daquele que as pronuncia, crença cuja produção não é da competência das palavras. (BOURDIEU, 1989 p. 14-15)

É com base na legitimidade das palavras que se pode afirmar que o processo de interação e comunicação não se fulcra apenas na elaboração de signos e troca espontânea deles, mas perpassam os poderes simbólicos socialmente e historicamente construídos. Nesse sentido, a linguagem serve como instrumento balizador desse poder simbólico instituido, criando um fosso entre o cidadão e a cidadã que procura o órgão jurisdicional.

Infere-se, portanto, que a linguagem jurídica, com seus excessos, é construida por meio do poder simbólico que se interpõe entre o jurisdicionado e a Justiça, cujo objetivo precipuo, na visão de Bourdieu (1989), é manter a distância e uma suposta independência entre o que ocorre no mundo social e o que é discutido no campo jurídico.

\section{Análise de um acórdão redigido em linguagem coloquial}

Diante de todos os aspectos que permeiam o acesso dos jurisdicionados ao Poder Judiciário, especialmente no que tange à produção de uma linguagem consonante com o letramento dominante, construido pelo poder simbólico, urge que profundas reflexões sejam feitas, objetivando a mudança desse quadro.

É notório que o processo de comunicação no espaço juridico assenta-se não na interação entre os agentes linguísticos, mas na construção de fronteiras de sentido exercidas por poderes simbólicos socialmente instituídos ou imaginados, como já ressaltado. Esse panorama evidencia a necessidade de uma mudança de mentalidade do Estado, através do Poder Judiciário, para reverter essa relação de distanciamento entre o cidadão que demanda a prestação jurisdicional e o Estado democrático de direito. Tal processo deve ser perpassado, obrigatoriamente, por um novo modelo do ato comunicativo.

É nesse sentido que se verifica um movimento de mudança de paradigma no que tange à tentativa de aproximação entre o cidadão demandante e 
o Poder Judiciário, demandado. A título de exemplo desse novo paradigma, tem-se a decisão de um juiz trabalhista, em sede de acórdão, convocado da $4^{\text {a }}$ Turma do Tribunal Regional do Trabalho da $4^{\text {a }}$ Região (RS), João Batista de Matos Danda. A decisão foi redigida pelo magistrado, relator do processo, em linguagem mais simples, ${ }^{2}$ para, segundo ele, aproximar o Judiciário da população.

A decisão emanada do magistrado teve grande repercussão dentro e fora do mundo jurídico, com ampla divulgação em blogs e sitios especializados, ou não, dada a linguagem inusitada utilizada pelo julgador no que se refere a textos dessa natureza. Criticado por uns, elogiados por outros, o fato é que o juiz conseguiu abrir a discussão sobre a possibilidade do uso de uma linguagem capaz de inserir o jurisdicionado no contexto das decisões judiciais.

O contexto em que se deu a decisão foi o Processo Trabalhista n. ${ }^{\circ}$ 0000869-29.2013.5.04.0241, em trâmite no estado do Rio Grande do Sul, em que um pedreiro pleiteava o reconhecimento de vínculo de emprego e indenização por danos morais após sofrer acidente em uma obra particular de propriedade de outrem.

A sentença prolatada em sede de $1 .^{\circ}$ grau considerou improcedentes os pedidos formulados pelo pedreiro. Em sede de recurso, o acórdão não reconheceu o vínculo empregatício, mas entendeu que o pedreiro teria direito a receber uma indenização e uma renda mensal a ser paga pelo dono da obra.

Para uma melhor análise, destacam-se alguns trechos da decisão. Cumpre esclarecer que os nomes das partes e da testemunha ouvidas no processo, bem como os nomes citados pela testemunha, foram omitidos. Assim, embora tenham sido amplamente divulgados em sítios oficiais da Justiça e blogs e por se tratar de decisão exposta no Diário Oficial, optou-se por denominar as partes citadas como sujeito 1 (pedreiro) e sujeito 2 (dono da obra), testemunha 1, trabalhador 1 , trabalhador $2 \mathrm{e}$ trabalhador 3. Seguem alguns trechos da decisão. ${ }^{3}$
O Juiz do Trabalho de Alvorada entendeu que o [sujeito 1] tinha prestado trabalho por conta própria, em regime de empreitada, e que não foi empregado do sujeito 2. Negou todos os direitos que reclamava. O pedreiro não se conforma e recorre. E o reclamado, sujeito 2 , com direito a se defender, diz que a sentença do Juiz está certa e quer que seja confirmada. $O$ processo veio de Alvorada para Porto Alegre e me toca dizer quem está com a razão, depois de olhar novamente todas as provas.

[...]

O Juiz de Alvorada ouviu os dois numa audiência e mais três testemunhas. Tem no processo fotos, documentos e perícia também. Depois de examinar tudo, deu razão ao dono da obra. [...]

Para julgar de novo, vou ler as declarações de todos mais uma vez e olhar os documentos. Pode ser que me convença do contrário. Mas pode ser que não. Vamos ver.

[...]

Além do mais, as testemunhas não provaram, nem que [sujeito 2] tivesse outras obras, nem que mandasse [sujeito 1] fazer trabalhos em outros locais, muito menos que além de açougueiro, tivesse firma no ramo da construção civil.

A [testemunha 1] pouco ajudou a esclarecer as coisas. Disse que em uma época, quando estava desempregado, [sujeito 1] convidou para trabalhar com ele em uma obra lá em Cachoeirinha. Mas não conhece o [sujeito 2], nem as pessoas que trabalharam na casa de [sujeito 2] no curso da construção da casa, como trabalhador 1, trabalhador 2, trabalhador 3 ou o "Índio". (DANDA, apud RODAS, 2015, s./p., grifos nossos)

Como visto, o jargão próprio do meio jurídico foi afastado, com a predominância clara de uma linguagem corriqueira e, pode-se dizer, até mesmo descuidada, do ponto de vista do meio jurídico, considerando o uso de uma variedade linguística não comum a esse meio, conforme se observa no emprego do verbo ter com sentido de existir ou haver.

Essa variação considerada não comum nos gêneros textuais produzidos pelos membros do judiciário, é de uso corriqueiro em linguagem coloquial, própria de contextos sociais mais informais. Trata-se do letramento vernacular em detrimento do letramento dominante, em uma clara intenção de privilegiar a interação direta entre as partes do processo e o Estado que julga, objetivo primeiro do ato comunicativo.

\footnotetext{
Disponivel em: https://www.conjur.com.br/2015-mai-25/juiz-faz-decisao-linguagem-coloquial-combater-juridiques. Acesso em: 20 jun. 2019. Os trechos foram recolhidos do documento disponivel em: https://www.conjur.com.br/2015-mai-25/juiz-faz-decisao-linguagem-coloquial-combater-juridiques. Acesso em: 20 jun. 2019.
} 
O próprio magistrado que proferiu a sentença, em entrevista ao sítio G1.globo, ${ }^{4}$ considerou que o trecho "para julgar de novo, vou ler as declarações de todos mais uma vez e olhar os documentos. Pode ser que me convença do contrário. Mas pode ser que não. Vamos ver", normalmente, seria escrito da seguinte forma:

Inconformado com a sentença, que julgou improcedente a ação, recorre o reclamante buscando sua reforma quanto ao vínculo de emprego e indenização por acidente de trabalho. Com contrarrazões sobem os autos a este tribunal. É o relatório. Passo a decidir. (DANDA, apud RODAS, 2015, s./p.)

Observa-se que a linguagem em que o trecho normalmente seria redigido seria de dificil entendimento para as partes que compõem a lide, não atingindo o objetivo maior do signo linguístico, que é a comunicação. Conforme assevera Bourdieu (1989), a linguagem, nessa situação, se transveste de poder simbólico.

Desta feita, o uso do letramento dominante funciona como um obstáculo ao acesso do cidadão comum, seja alfabetizado ou não, à Justiça, o que acaba por estabelecer uma posição assimétrica ocupada entre as partes do processo, e, consequentemente, afastando os cidadãos e cidadãs comuns do pleno acesso à jurisdição.

Verifica-se ainda que, na intenção de suscitar uma reflexão sobre a temática, o julgador, de forma proposital, excedeu o uso da variedade coloquial, podendo-se até afirmar que houve a extrapolação dos limites da linguagem coloquial de forma, passando, assim, a mensagem de que é possivel aproximar a Justiça do cidadão, com o uso de um discurso mais acessivel às partes da demanda judicial. Essa intenção ficou bem clara no trecho em que o juiz estabelece o direito de indenizar, como segue:

(1) Dano moral - Se a pessoa sofre um abalo, uma tristeza, um constrangimento ou uma dor, por culpa de outro, tem direito a receber uma indenização de quem lhe causou isso. Não é qualquer dorzinha que dá direito a uma compensação em dinheiro, mas a que o sujeito 1 teve e tem, certamente, é de indenizar. Caiu, ficou desacor- dado, foi para o hospital, sofreu procedimentos, medo das sequelas e a dor que até agora sente em alguns movimentos do corpo, além de ficar sem poder trabalhar no seu oficio.

Essa indenização serve para amenizar um pouco o sofrimento do sujeito, mas também serve para Itamar lembrar que tem obrigação de cuidar da segurança daqueles que trabalham na sua casa, mesmo quando não são empregados.

A lei não fixa valores para cada caso e o Juiz tem que fazer isso com bom senso.

Não pode ser uma indenização tão pesada que vire um inferno para seu [sujeito 2] pagar; nem muito pouco, porque aí ele paga sem problemas e não se importa se amanhã ou depois outro acidente acontece em sua casa (DANDA, apud RODAS, 2015, s./p., grifos nossos)

Assim como o magistrado da sentença sob análise conceituou o dano moral, também o fez com o dano matrimonial, e como o valor desse dano foi mensurado. Vejamos:

Dano patrimonial - Esta indenização compensa pela capacidade de trabalho que o [sujeito 1] perdeu e é certo que ficou com limitações de movimentos para exercer o seu oficio ou outros do tipo.

Tem uma tabela que ajuda o perito médico a fixar, em números, o tamanho desse prejuizo. Aqui, ele disse que a coluna de [sujeito 1], na altura do peito(tórax) está bem comprometida: e que na altura da cintura, a coluna também tem lesão, mas não é tão grave. (DANDA, apud RODAS, 2015, s./p.)

Na jurisprudência e em toda a literatura jurídica, o conceito de dano patrimonial aparece de forma pomposa, com o uso de jargões do universo jurídico. No intuito de aproximar as partes do julgador da demanda. Novamente o magistrado usou o verbo ter no sentido de existir, uma construção consagrada em situações cotidianas de interação, para se referir à tabela usada para auferir o valor do dano patrimonial.

Não obstante a crítica a que foi alvo o magistrado pelo uso da linguagem empregada, entende-se que o uso de expressões e vocábulos do cotidiano na decisão prolatada, teve como intuito, como já ressaltado, suscitar reflexões em torno do uso exagerado da linguagem e da cultura do chamado "juridiquês", 
que é o rebuscamento da linguagem jurídica.

Como visto, a análise desses trechos demonstra o uso não padrão da língua, o que pode ser considerado para alguns um excesso na linguagem empregada; em contrapartida, verifica-se ser possivel a substituição de termos técnicos e expressões latinas por uma linguagem mais simples e próxima daqueles que diretamente são atingidos pelas decisões judiciais. Quanto a isso, é preciso considerar que restringir o acesso do cidadão comum, cuja prática de letramento geralmente não se funda no letramento dominante, aos discursos do mundo jurídico é negar a esses jurisdicionados o verdadeiro acesso à Justiça, tal qual apregoa o texto constitucional. Nesse sentido, iniciativas como a que está em análise servem para se refletir sobre uma tomada de decisão e a adoção de uma nova postura frente à necessidade de inserção do cidadão nas decisões jurídicas.

Por outro quadrante, no que tange ao poder simbólico, Bourdieu (1989) afirma que o capital simbólico adquirido pelos agentes do campo jurídico e seu poder decisório representam a palavra pública enunciada em nome de todos, veredito que resolve os conflitos reconhecidos universalmente.

O autor acrescenta que os ritos constituintes do universo jurídico, encarnado por uma autoridade constituida, são iniciados pela linguagem, portanto, mesmo que exista toda uma estrutura e mecanismos que sustentam esse poder simbólico, é possivel minimizar seus impactos, que funcionam como instrumentos de fronteira entre os agentes estatais e o cidadão comum.

Dessa forma, entende-se que o uso de uma linguagem despojada de rebuscamento, de purismo e da tecnicidade própria da seara jurídica proporcionará a democratização do acesso ao conteúdo das decisões judiciais, minimizando assim a relação de dominação decorrente da dificuldade de entendimento dessas decisões, concretizando o princípio constitucional de acesso à Justiça.

\section{Considerações finais}

Os textos juridicos, emanados dos agentes públicos que deles fazem uso, devem contribuir para a eficácia da aplicação e compreensão do direito, sem abusos de incompreensão. Nessa perspectiva, privilegiar o letramento dominante em detrimento do letramento vernacular é condenar o jurisdicionado ao isolamento e ao distanciamento da Justiça, numa afronta aos princípios que regem o Estado democrático de direito.

A distorção e o uso abusivo do letramento dominante a fim de elitizar a linguagem juridica, instrumentalizando-o como forma de poder, trazem consequências irreversíveis à Justiça e à sociedade. Toda a discussão sobre a linguagem das decisões emanadas dos juizes no âmbito do Poder Judiciário, cujas respostas encontram amparo no letramento dominante e no poder simbólico de Bourdieu (1989), levam à compreensão dos fenômenos que perpassam a linguagem juridica, podendo elucidar os motivos de manutenção dessa linguagem tal como ela tem se colocado para a sociedade: distante e inacessivel.

A linguagem só existe enquanto realização social, logo, se a linguagem jurídica tem uma dimensão dialógica (FIORIN, 2008), necessário estabelecera interação com o jurisdicionado. O uso de um código gera a exclusão de determinado público, o que, no caso dos textos emanados dos julgadores no âmbito jurisdicional, afronta o princípio de acesso à Justiça, como já exaustivamente afirmado, maculando, assim, a relação dialógica da linguagem.

Em se tratando de linguagem jurídica, cujo letramento dominante e o preciosismo linguístico prevalecem, como inserir o cidadão nessa relação dialógica? Como discutido no bojo do artigo, o rebuscamento e excessos terminológicos presentes nas decisões emanadas dos iminentes julgadores revelam um arrogo próprio das relações assimétricas hierarquizadas, que estruturam o poder simbólico, consoante ideia de Bourdieu (1989).

Como visto na análise do acórdão, instaurar a simplificação da linguagem jurídica mostra-se necessário, com o fito de efetivar o direito de acesso à Justiça. Isso posto, constata-se maior eficácia naquelas iniciativas que incentivam o legislador e os profissionais do Direito a redigirem com clareza e objetividade.

Toda a argumentação tecida ao longo deste artigo teve a intenção de levar o leitor ao con- 
vencimento de que o acesso à Justiça é direito constitucional do cidadão brasileiro e que o uso de uma linguagem jurídica clara, acessivel e objetiva é determinante para a efetivação desse direito. A manutenção dessa linguagem dominante, distante dos individuos jurisdicionado, serve apenas como um dos pilares de sustentação do poder simbólico, em detrimento do verdadeiro sentido da língua, que é estabelecer relações comunicativas entre os seus falantes. Pode-se afirmar, ainda, que todo esse distanciamento entre o cidadão que procura a Justiça e o conhecimento do mundo jurídico, pelo uso de uma linguagem inacessivel e distante pelos agentes públicos que atuam nesse espaço, acaba por fomentar uma postura de repulsa e uma imagem caricata e de prepotência de um espaço que deveria ser de acolhida.

\section{Referências}

BARTON; David; HAMILTON, Mary. Local literacies: Reading and writing one Community. London and New York: Routledge, 1998.

BOURDIEU, Pierre. O poder simbólico. 6. ed. Rio de Janeiro: Bertrand Brasil, 1989. Disponivel em: http:// www.ipeq.quimica.ufg.br/up/426/o/bourdieu_pierre._o_poder_simbolico.pdf. Acesso em: 20 jun. 2019.

FIORIN, José Luiz. Introdução ao pensamento de Bakhtin. São Paulo: Ática, 2008

FREIRE, Paulo. Ideologia e educação: reflexões sobre a não neutralidade da educação. Rio de Janeiro: Editora Paz e Terra, 1981.

HEATH, Shilei Brice. Protean shapes in literacy events: ever-shifting oral and literate traditions. In. TANNEN, D. (ed.). Spoken and written language: exploring orality and literacy. Norwood, N. J.: Ablex, 1982. p. 93

KLEIMAN, Ângela B. (org.). Os significados do letramento. Campinas: Mercado de Letras, 1995.

MAGALHÃES NETO, Pedro R. Eventos de letramento em situação carcerária. Teresina: Editora F. G. Com de Equipamentos e Serviços, 2017.

MORTATTI, Maria do Rosário. Longo. Educação e Letramento. São Paulo: UNESP, 2004

RIOS, Guilherme V. Letramentos do mundo da vida e letramentos de sistemas: revisitando os letramentos dominantes. Revista Signótica - UFG, Goiás, v. 25, n. 2, 2013.

RODAS, Sérgio. Manifesto antiformalista. Revista Consultor Juridico, 25 maio 2015. Disponivel em: https:// www.conjur.com.br/2015-mai-25/juiz-faz-decisao-linguagem-coloquial-combater-juridiques. Acesso em: 20 jun. 2019
SOARES, Magda. Novas práticas de leitura e escrita: letramento na cibercultura. Educação e Sociedade, Campinas, v. 23, n. 81, p. 143-160, dez. 2002. Disponivel em: http://www.cedes.unicamp.br. Acesso em: 20 jun. 2019

STREET, Brian. (org) Cross-Cultural Approaches to Literacy. Cambridge: Cambridge University Press, 1993.

STREET, Brian V. Literacy in theory and practice. Cambridge: Cambridge University Press, 1984.

TFOUNI, Leda Veridiani. Adultos não alfabetizados: o avesso do avesso. Campinas: Pontes, 1988.

TFOUNI, Leda Veridiani. Letramento e alfabetização. São Paulo: Cortez, 1995

\section{Luzia Fernandes}

Especialista em Linguística pela Universidade Estadual do Piaui (UESP/PI), em Teresina, PI, Brasil; professora do Colégio Militar Tiradentes V, Timon, MA, Brasil.

\section{Endereço para correspondência}

Luzia Fernandes do Nascimento

Universidade Federal do Piauí

Campus Universitário Petrônio Portela, s/n

Centro de Ciências Humanas e Letras, sala 322

Ininga, 64049-550

Teresina, PI, Brasil 